\title{
Spanningsvelden in de klinische leeromgeving. Een exploratieve studie van stage-ervaringen
}

\author{
A. Deketelaere, G. Kelchtermans, E. Struyf, P. De Leyn
}

\section{Samenvatting}

Probleemstelling: De stage (het co-assistentschap) is een essentieel onderdeel van de opleiding tot arts, maar niet alle stages leiden tot de verhoopte leerresultaten. In dit artikel rapporteren we over een exploratief onderzoek naar de determinanten van de stage-ervaringen. Uitgangspunt is de idee dat die ervaring in belangrijke mate bepaald wordt door de betekenisvolle interactie tussen stagiair en stageomgeving (in het bijzonder de stageleiders).

Onderzoeksopzet en methodologie: Door middel van interpretatieve methodieken (student shadowing, interviews) werden gegevens verzameld bij acht stagiairs en hun stageleiders in twee perifere ziekenhuizen. De interpretatieve analyse van de gegevens werd ter validering voorgelegd aan focusgroepen van stagiairs en stageleiders.

Resultaten: De analyse resulteerde in het identificeren van vijf componenten die toelaten de stage-ervaringen in kaart te brengen en te begrijpen. Elke component blijkt beschreven te kunnen worden in termen van een spanningsveld. Deze componenten zijn: (1) de stageagenda (werken versus leren), (2) de begeleidershouding (evaluator versus coach), (3) de stagecultuur (beroepsgericht versus opleidingsgericht), (4) de leerhouding van de stagiair (receptief versus pro-actief) en (5) de aard van het leerproces (informeel versus formeel). De spanningsvelden in de respectievelijke componenten dienen niet gezien te worden als op te lossen tegenstellingen, maar zijn als zodanig constitutief voor de stage-ervaring. De stagiairs bevinden zich onvermijdelijk en voortdurend in de dynamiek van die spanningsvelden en dit bepaalt de impact van de stage.

Relevantie en besluit: De componenten en spanningsvelden vormen een conceptueel kader dat toelaat de stage-ervaringen systematischer in kaart te brengen en te analyseren. Voor de stagiairs helpt het om de ervaringen te duiden en het eigen leren te sturen. Aan stageleiders en opleidingsverantwoordelijken biedt het een begrippenkader om analytisch meer inzicht te verwerven in de betekenis van stage-ervaringen en om de kwaliteit van stageplaatsen als klinische leeromgeving te evalueren. (Deketelaere A, Kelchtermans G, Struyf E, Leyn P De. Spanningsvelden in de klinische leeromgeving. Een exploratieve studie van stage-ervaringen. Tijdschrift voor Medisch Onderwijs 2005;24(3):103-112.)

\section{Probleemstelling}

De stage is een essentieel onderdeel van de opleiding tot arts. Het is de aangewezen omgeving om de reeds verworven kennis te toetsen aan de klinische praktijk en om zo de basiscompetenties, als een geïntegreerd geheel van kennis, vaardigheden en attitudes te verwerven. ${ }^{1}$ Stage-ervaringen dragen ook bij tot de beroepssocialisatie als arts. ${ }^{2}$
Toch leidt het plaatsen van studenten in een stagesituatie niet automatisch tot de gewenste leerresultaten. ${ }^{3-6}$ De effectiviteit van de stage wordt in belangrijke mate bepaald door de kenmerken van de stagiair, de kenmerken van de stageplaats en de betekenisvolle interactie tussen beide. Stageplaatsen verschillen sterk in de aard en omvang van de leerkansen die ze bieden. ${ }^{7}$ Daarnaast grijpen stagiairs ook niet altijd 
de geboden leerkansen ten volle aan. ${ }^{8}$ Een belangrijk knelpunt heeft te maken met de aard van de stageplaats. ${ }^{9}$ Het gaat om een klinische omgeving, waarin de arts de zorg voor patiënten opneemt. Het authentieke karakter van deze beroepscontext maakt enerzijds de stage pas mogelijk, maar leidt anderzijds tot interferentie met de idee van een stageplaats als leeromgeving. ${ }^{10}$ Arts en stagiair geven aan de stagesituatie op een verschillende manier betekenis. Onderzoek (o.m. vanuit een cognitief-psychologische benadering) wijst erop dat die betekenisgeving in belangrijke mate het leren bepaalt. ${ }^{11}$ Daarom is het essentieel om preciezer inzicht te verwerven in de complexe, betekenisvolle interactie tussen stagiair en stageomgeving waarin de stageleider (en zijn/haar betekenisgeving) van cruciaal belang is.

\section{Onderzoeksopzet en methodologie}

We rapporteren hier over een exploratief onderzoek dat zich richtte op het in kaart brengen en analyseren van de stage-ervaringen. Omdat de betekenisgeving door de betrokkenen centraal stond in de probleemstelling, lag de keuze voor interpretatieve onderzoeksmethoden voor de hand. Het onderzoek vond plaats in twee perifere ziekenhuizen die werden geselecteerd op basis van hun grootte (een klein en een middelgroot perifeer ziekenhuis) en hun nabijheid bij het opleidingsinstituut.

In elk ziekenhuis werden er bij vier stagiairs gegevens verzameld door middel van 'student shadowing', ${ }^{12}$ aangevuld met informele gesprekken en semi-gestructureerde interviews. ${ }^{13}$ Concreet werden de stagiairs elk gedurende één stagedag gevolgd (geobserveerd) en tussendoor bevraagd over hun percepties, interpretaties, et cetera. Voor zover mogelijk werden telkens ook de stageleiders bevraagd.
Daarnaast werd van elke stagiair en van (één van) hun stageleider(s) een semi-gestructureerd interview afgenomen (30 à 60 minuten). Deze interviews vonden plaats op dezelfde dag als de student shadowing. In het interview werden hun algemene opvattingen over de mogelijkheden en knelpunten van de stage als klinische leeromgeving meer systematisch geëxploreerd. Op die manier werden zowel de percepties van de stagiairs als van hun stageleiders in kaart gebracht. Tegelijkertijd dienden de interviews voor het verzamelen van relevante contextinformatie én voor het toetsen van voorlopige interpretaties. De combinatie van observatie en interview maakte het mogelijk om zowel de opvattingen (verbale theorie) van stagiairs en stageleiders te achterhalen, als om deze te vergelijken met hun feitelijk handelen gedurende die stagedag (theorie in action). ${ }^{14}$ Door deze vorm van datatriangulatie werd de validiteit van de onderzoeksgegevens bewaakt. ${ }^{15}$

Alle data per stagiair werden samengebracht in één casestudie. ${ }^{16-17}$ Vertrekkend van de drie elementen uit de probleemstelling (leren wordt bepaald door de interactie tussen stagiair en stageomgeving) werd een interpretatieve analyse gemaakt per case (verticale of 'within case'-analyse). In een tweede fase werden de acht gevalsstudies onderling systematisch vergeleken op gelijkenissen en verschillen, terugkerende patronen, et cetera (horizontale of 'cross case'-analyse).

De resultaten uit de analyse werden in focusgroepen (uit elk ziekenhuis telkens één groep met stageleiders en één met stagiairs, andere dan de geschaduwde stagiairs) ter validering voorgelegd. Een conclusie werd valide beschouwd als de groep zich herkende in het resultaat. De resultaten werden ook voorgesteld op een studiedag voor stageleiders van alle opleidingsziekenhuizen, wat als een bijkomende validering geldt. 


\section{Resultaten}

De analyse van de gevalsstudies resulteerde in vijf componenten waarmee het stagegebeuren beschreven kan worden en die dus een verfijning vormen van de drie componenten uit de probleemstelling (stagiair, stageplaats en de interactie ertussen). Deze vijf componenten zijn: de stageagenda, de stagecultuur, de begeleidershouding van de stageleider, de leerhouding bij de stagiair en de aard van het leerproces. Elke component blijkt daarenboven gekenmerkt te worden door een spanningsveld. Hierna bespreken we de componenten en lichten we de spanningsvelden toe.

\section{De stageagenda: werkend leren of lerend werken}

Waartoe dient de stage? Welke activiteiten vinden er plaats? Of nog: wat is de stageagenda? Dit is een eerste component die het stagebeuren bepaalt. Twee verschillende agenda-invullingen strijden om dominantie: ligt de klemtoon op leren of op werken? Mogen studenten leren in ruil voor te leveren arbeidsprestaties (de stagiair als extra beroepskracht)? Of wordt leren beschouwd als iets wat onlosmakelijk verbonden is met het werken en er rechtstreeks uit voortvloeit? Het is duidelijk dat leren en werken hier samenhangen, maar toch bestaat er een spanningsverhouding tussen beide. Zeker wanneer men als leerresultaat meer beoogt dan louter het imiteren van een reeks technische handelingen.

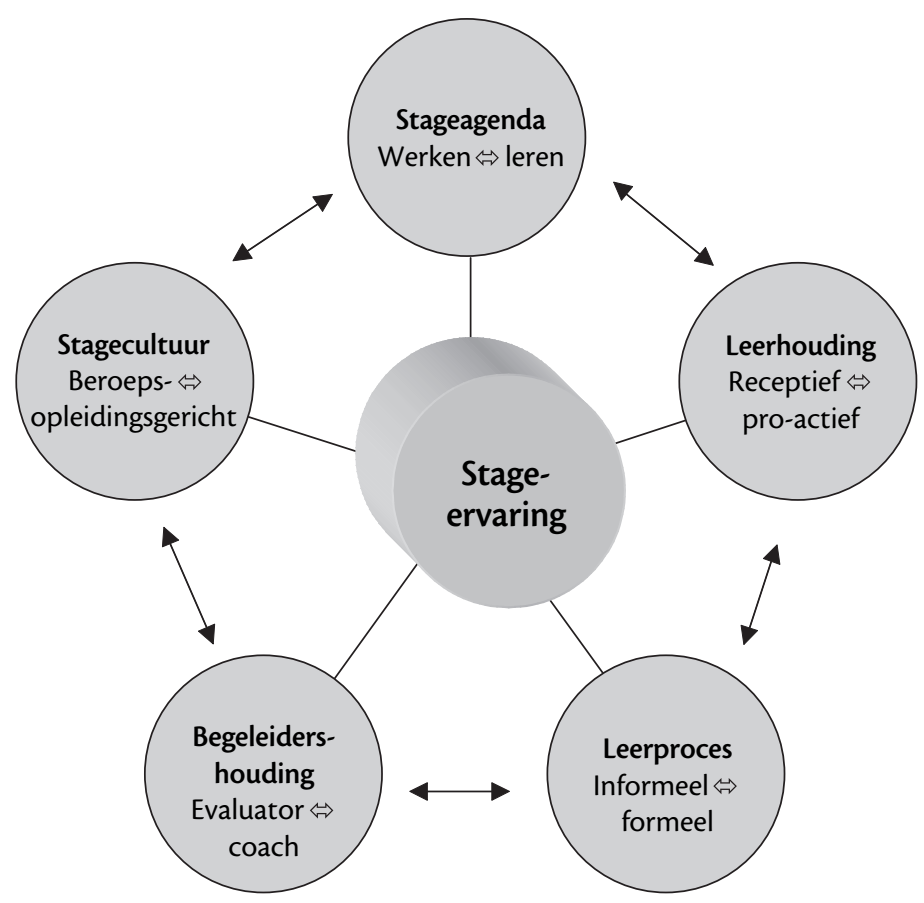

Figuur 1. Overzicht van de componenten en hun spanningsvelden. 
De volgende citaten uit de casestudies illustreren deze spanningsverhouding en de gevolgen ervan voor de stagebeleving. De eerste twee citaten zijn van stageleiders, de volgende van stagiairs:

"Hier, in de praktijk moeten ze tonen wat ze waard zijn: lange dagen maken zonder rustpauzes, stressbestendigheid uittesten, fysiek opbouwen..." "Het is een eerste kennismaking met de praktijk, ze zijn toerist: ze krijgen de kans af te tasten wat hen aanspreekt, dit helpt hen bij hun latere beroepskeuze."

"N. vertelt dat ze zich op de dienst overbodig voelt. Het werk is perfect georganiseerd zodat zij alle tijd heeft om te leren. Maar omdat ze alleen maar kan toekijken, verveelt ze zich en loopt ze wat verloren. Een andere studente heeft precies de omgekeerde ervaring. $\mathrm{Zij}$ klaagt dat ze nooit afwezig kan zijn op haar dienst. Ze moet voor de zaaltoer alle documenten klaarleggen, labo's aanvragen, patiënten opvolgen, et cetera. Ze heeft geen tijd om iets op te zoeken of consultaties te volgen."

Zowel wanneer de stagiair niets om handen heeft, geen kans krijgt om te werken, als wanneer hij/zij teveel dient te werken, komt het leren uit de (werk)ervaringen in het gedrang. Ofschoon alle respondenten impliciet uitgaan van de opvatting dat men leert door te werken en dat beide dus in sterke mate samenhangen, kunnen ze allemaal voorbeelden aanhalen van opdrachten en taken zonder enig leerrendement (bijvoorbeeld: voor de zoveelste keer assisteren bij een liesoperatie of een hele voormiddag administratie afhandelen). Onderzoek bevestigt dat stagiairs veel tijd besteden aan activiteiten met weinig vormende waarde. ${ }^{6}$ Het is echter interessant om te merken dat stagiairs zelf met het spanningsveld omgaan vanuit een compensatiebenadering. Zolang ze de (weinig vormende) werkopdrachten zien als een tegenprestatie voor de extra tijd die de stageleider in hen investeert, tillen ze er niet zwaar aan. Het gevoel (mis-/ge-) bruikt te worden als gratis werkkracht ontstaat wanneer de balans tussen leren en werken zoek is en vooral wanneer ze zelf niet meer kunnen beslissen over hun tijdsinvulling. Meteen wordt duidelijk dat een analyse van stage-ervaringen aandacht moet hebben voor betekenisgeving door de betrokkenen. Het spanningsveld betreft immers niet het werken of leren op zich, maar de wijze waarop de betrokkene de verhouding tussen beide als legitiem percipieert. Dit neemt evenwel niet weg dat wanneer stagiairs onder te hoge werkdruk komen te staan, de kwaliteit van hun leerervaringen daalt. ${ }^{18}$

\section{De begeleidershouding: evaluator versus coach}

Een opleider in de klinische context is nooit alleen maar opleider, hij/zij is altijd ook behandelend arts met verantwoordelijkheden tegenover patiënten. In die zin ervaart elke stageleider een conflict tussen zijn/haar engagementen tegenover de patiënt en deze tegenover de stagiair. ${ }^{8}$ Maar ook tegenover de stagiair neemt de stageleider noodgedwongen verschillende rollen op. ${ }^{10}$ Het meest herkenbaar zijn de momenten waarop de stageleider formeel inhouden aanbrengt of vaardigheden demonstreert. De stageleider neemt de teaching-rol op.

Die duidelijkheid is er niet altijd en sommige rollen staan onderling in een spanningsverhouding. Dat is het geval met de rol van coach enerzijds en deze van evaluator anderzijds. Heel vaak maken stageleiders informeel en terloops opmerkingen, waarbij het voor de stagiair niet duidelijk is in welke mate dit bedoeld is als grapje, 
aansporing of ernstige kritiek. Maar ook als stageleiders geen opmerkingen maken, denken stagiairs dat ze het niet goed doen: "Ik wist totaal niet waar ik aan toe was. Ik had helemaal geen idee of ik nu goed bezig was of niet. Ik had nog liever gehad dat de stageleider mij zegt wat ik allemaal fout deed, dan dat hij helemaal niets zegt."

Zeker bij de aanvang van de stage zijn stagiairs alert op (non-)verbale signalen van stageleiders die hen feedback verschaffen over hun optreden, omdat ze weinig andere referentiekaders hebben. Stageleiders zijn zich hiervan onvoldoende bewust. Ze differentiëren in hun gedrag ook niet echt tussen coaching en evaluatie. Met coaching bedoelen we die interacties waarbij de stageleider de leeractiviteiten van de stagiair structureert, bijvoorbeeld door aan te sporen om een patiënt zelfstandig te onderzoeken, expliciet te vragen welke vragen de stagiair nog heeft of op het einde van de consultatie stil te staan bij wat de stagiair vandaag allemaal geleerd heeft. In de praktijk blijkt coaching nogal eens gelijk te staan met 'zeggen dat de stagiair het goed gedaan heeft'.

Uit de literatuur is bekend dat supervisie - als overkoepelende term voor ondersteuning, begeleiding, kwaliteitsverzekering en evaluatie ${ }^{19}$ - tijdens de stage dikwijls een probleem vormt, omdat ze er vaak gewoon niet is of omdat ze niet gebaseerd is op directe observatie. ${ }^{1}$ Onze data bevestigen deze conclusie.

Zowel stagiairs als stageleiders ervaren dit spanningsveld het sterkst wanneer dezelfde persoon zowel de begeleiders- als de evaluatierol opneemt. Als een stageleider een vertrouwensband opbouwt met de stagiair is het moeilijker de nodige afstand te bewaren om op het einde van de stage het objectieve cijfer toe te kennen dat vanuit het opleidingsinstituut gevraagd wordt. Omgekeerd is het voor een stagiair minder evident om tijdens de stage tegenover een stageleider zwakke kanten toe te geven als deze stageleider ook nog punten moet geven.

\section{Stagecultuur: beroepsgericht versus opleidingsgericht}

Binnen de opleiding tot arts aan de Katholieke Universiteit Leuven werd ervoor gekozen om stagiairs toe te kennen aan een dienst en niet aan een stageleider. Dit heeft als voordeel dat een stagiair binnen één dienst de werkwijze van verschillende stageleiders leert kennen. Nadeel is soms dat geen enkele stageleider de stagiair van nabij opvolgt en de stagiair wat verloren loopt.

Op sommige diensten vormt de opleiding van stagiairs een integraal onderdeel van de organisatiedoelen. We spreken dan van een opleidingsgerichte cultuur: "Op de dienst is er een onthaalbrochure en taakomschrijving op maat van de stagiair. De stageleider bespreekt aan het begin van de stage met de stagiair waar zijn/haar specifieke belangstelling naar toe gaat."

Op andere diensten is er weinig of geen expliciete aandacht voor die opleidingsfunctie. De dienst wil in de eerste plaats een efficiënte zorg voor de patiënten waarborgen. Hier domineert een beroepsgerichte cultuur. Van stagiairs wordt verwacht dat ze zich in die organisatie inschakelen. Een beroepsgerichte cultuur betekent niet dat er geen zinvolle leerervaringen kunnen plaatsvinden, maar voor de stagiairs is het wel een groot verschil om in een beroepsgerichte dan wel een opleidingsgerichte omgeving te werken. Stagiairs die gemakkelijk initiatief nemen (pro-actief zijn, zie verder), kunnen zich goed thuis voelen in zo'n cultuur en er ook veel leren. Meer receptief ingestelde stagiairs krijgen er vaker de indruk aan hun lot overgelaten te worden en verloren te lopen. 
Het mag duidelijk zijn dat ook de spanning tussen opleidingsgerichte en beroepsgerichte cultuur in elke stageplaats aanwezig is: in elke klinische leeromgeving geldt tegelijk de zorg voor patiënten. Dit spanningsveld wordt nog versterkt omdat de stageleiders van het opleidingsinstituut geen honorarium ontvangen voor de tijd die ze aan opleiding besteden. Het opleidingsinstituut heeft weinig middelen om opleidingstijd af te dwingen.

\section{De leerhouding bij de stagiair: receptief versus pro-actief}

In onderzoek naar de effectiviteit van de stage als leeromgeving blijkt de variatie tussen studenten meestal veel groter dan de variatie tussen disciplines. ${ }^{1}$ Dit wijst op het belang van studentenkenmerken als determinant voor het leren. Daarenboven stelt de stageplaats als klinische omgeving specifieke eisen aan de lerende. In tegenstelling tot de sterk voorgestructureerde academische leeromgeving uit de preklinische jaren, is de klinische context veel meer open en ongestructureerd. Van de student-stagiair wordt een actieve, meer zelfsturende opstelling verwacht. ${ }^{20}$ Maar vanuit hun vooropleiding zijn studenten hiertoe niet echt toegerust. ${ }^{21}$ De overstap van het leren 'op de schoolbanken' naar het leren in de klinische leeromgeving is voor veel studenten dan ook moeilijk. ${ }^{22}$

De data in ons onderzoek maken duidelijk dat de attitude of leerhouding van de stagiair een belangrijke impact heeft op de leerervaringen. "Tussen twee operaties heeft S. een uurtje tijd om consultaties bij te wonen. Ze ziet er tegen op zich helemaal om te kleden en blijft in het operatiekwartier." "N. krijgt de indruk niets meer bij te leren tijdens de consultaties. Ze legt zichzelf op om het volgende uur eens speciaal te letten op de interactiewijze tussen de arts en patiënt."
Er duikt een spanning op tussen een afwachtende, ontvangende houding (receptief) enerzijds en een houding van initiatief nemen, vragen stellen en zo zelf de leermogelijkheden mee creëren (pro-actief) anderzijds. Beide houdingen maken leerervaringen mogelijk, maar stagiairs die van nature reeds extravert, assertief of enthousiast zijn, hebben een enorm voordeel. Die pro-actieve houding wordt door hun stageleiders (vaak terecht) gezien als een blijk van motivatie, waardoor deze studenten vaak meer leerkansen (en meestal ook betere beoordelingen) krijgen .

Toch betekent een meer afwachtende, receptieve houding van de stagiair niet automatisch dat de motivatie of inzet minder is. Stagiairs vragen zich vaak af hoe ze overkomen of ze zoeken naar hun plaats op de dienst ('Hoe zien ze mij?'; 'Doe ik het wel goed?'; 'Loop ik niet in de weg?'). Daardoor houden ze zich - zeker bij aanvang van de stage - op de achtergrond. In een aantal gevallen werd deze opstelling door stageleiders ten onrechte beschouwd als gebrek aan interesse of gemakzucht.

Dit spanningsveld bestaat er dus in dat studenten telkens weer moeten 'aftasten' welke houding ze best kunnen aannemen bij welke stageleider, in hoeverre ze zelf pro-actief leerkansen moeten opzoeken dan wel of ze juist leerkansen mogelijk maken door zich nieuwsgierig-afwachtend op te stellen.

\section{De aard van het leerproces: informeel of formeel}

Dat er tijdens stages geleerd wordt, behoeft weinig betoog, maar veel minder duidelijk is hoe en wat er precies geleerd wordt. Zonder volledig recht te doen aan de complexiteit van het leerproces tijdens stages, blijkt uit de data de spanning tussen twee grote categorieën van leerprocessen. In een aantal gevallen vloeit het leren voort uit doelgerichte acties van de stagiair en 
de stageleider. Leersituaties, opdrachten, taken worden dan bewust aangegrepen of zelfs gepland om de stagiair leerkansen te bieden.

Daarnaast vindt er in de klinische omgeving ook veel informeel en incidenteel leren plaats. ${ }^{6}$ Deze leerkansen dienen zich aan, onafhankelijk van de intenties van stageleiders.

"Tijdens de student shadowing observeerde de onderzoekster hoe een stageleider een klinisch onderzoek anders aanpakte dan de stagiair het net daarvoor had gedaan, hoe een arts tijdens een consultatie de partner discreet de mond snoerde om de patiënt zelf te laten praten, hoe een kind zich anders gedroeg dan wat men zou verwachten bij die leeftijdsgroep, ... Ze vroeg zich af of de stagiair dit ook opgemerkt had."

Meer nog dan bij de formeel geplande leersituaties vormen in de informele leermomenten nauwkeurige observatie, aandacht en alertheid voorwaarden tot effectief leren. Aanwezigheid in die situatie of observatie op zich volstaan niet, omdat het praktijkgebeuren te complex is. De ervaren arts selecteert uit zo'n praktijksituatie wat belangrijk is en wat niet. Voor een stagiair blijft veel dikwijls onopgemerkt, omdat hij/zij de kaders niet heeft. Wanneer het leren geformaliseerd wordt door bepaalde aspecten expliciet onder de aandacht te brengen, is de kans groot dat de stagiair deze relevante zaken wel opmerkt. Men ziet immers slechts datgene, waarop men de aandacht richt.

Een stagiair vertelt dat ze na een thematische 'krans' (= seminarie voor stagiairs) over het screenen van zwangere vrouwen veel meer opmerkte tijdens de consultaties gynaecologie. Ze besluit: "Vroeger ontging mij veel omdat ik de kaders niet had."
Omdat de pathologie die zich in de klinische leeromgeving aanbiedt onvoorspelbaar is, moet men zich voor het leren uit de praktijk ook kunnen overleveren aan wat zich in die praktijk op dat moment aandient. Voor studenten die in de academische leeromgeving gewoon zijn alles onder controle te hebben, is dit soms frustrerend. Een stagiair verwoordde het gevoel “... overal en altijd te laat te komen en zo de meest interessante cases te missen."

Opleidingen investeren veel in het formaliseren en planmatig organiseren van leer-ervaringen tijdens de stage. ${ }^{23-24}$ Men laat stagiairs bijvoorbeeld werken met competentielijsten, ${ }^{25}$ logboeken ${ }^{8}$ of men laat hen leerdoelen formuleren. ${ }^{26}$ Toch blijkt uit onderzoek dat dit formaliseren niet altijd tot een groter leerrendement leidt. Daarenboven houdt formaliseren het gevaar in dat het 'voldoen' aan de opgelegde eisen doel op zich wordt en er weinig of geen aandacht is voor andere relevante leerkansen. Men is immers gefocust op dat wat 'afgevinkt' kan worden. Een stageleider haalt een anecdote aan uit z'n eigen buitenlandse stage, waarbij stagiairs voortdurend met checklist en pen achter de stageleider aanhollen om de noodzakelijke handtekeningen als bewijs voor verrichte vaardigheden te verzamelen.

De spanning tussen informeel en formeel leren bestaat erin dat de stagiair voldoende ruimte en vrijheid krijgt om in te gaan op de leerkansen die zich aandienen, terwijl tevens gewaarborgd wordt dat hij/zij zich tijdens het leren richt op die zaken die het opleidingsinstituut belangrijk vindt. Stagiairs geven aan dat ze naast het leren uit en van de praktijk nood hebben aan formele teachingmomenten waarin kaders opgefrist of aangereikt worden. Tegelijkertijd moeten stageleiders de studenten alert houden voor het per definitie onvoorspelbare van klinische situaties en de onverwachte leerkansen die hieruit voortvloeien. 


\section{Relevantie}

De bijdrage van dit exploratief onderzoek is in de eerste plaats conceptueel van aard. De onderscheiden componenten én hun spanningsrelaties vormen een begrippenkader dat toelaat om stage-ervaringen analytisch te beschrijven en te begrijpen. Deze spanningsvelden mogen niet beschouwd worden als uitersten op een continuüm, waarbij het ene wenselijk en het andere onwenselijk is. De spanningsvelden zijn als zodanig inherent aan en dus constitutief voor de stage-ervaring. Een stagiair staat per definitie altijd in elk van deze spanningsvelden, maar zijn/haar positie kan erin verschuiven, afhankelijk van bijvoorbeeld het tijdstip (begin/einde van stage), specifieke ervaringen in andere stageplaatsen, een gevoel van professionele competentie, zelfvertrouwen, betekenisgeving, et cetera.

Deze bijdrage heeft ook praktische relevantie. Uit onze ervaringen met dit begrippenkader blijkt dat het zowel voor stageleiders als voor stagiairs een bruikbaar concept is om het gesprek aan te gaan over de kwaliteit en de optimalisatie van de stage als leeromgeving. Tijdens nascholingen voor stageleiders werd het hier ontwikkeld begrippenkader gebruikt om hun opvattingen over hun dienst als leeromgeving te bespreken. Deze opvattingen beinvloeden immers in belangrijke mate de wijze waarop ze met stagiairs omgaan. ${ }^{27}$ Een reflectie over de componenten en spanningsvelden maakte hen bewust van hun eigen positie en het feit dat dit niet de enig mogelijke is. Het hielp hen ook om scherper de (wisselende) perspectieven van de stagiair te zien.

Vaak wordt voorgesteld om het leerrendement uit stages te verhogen door stagiairs zelf verantwoordelijk te maken voor hun leren. ${ }^{7}$ Studenten zijn echter neofieten in het zelf sturen van hun leren in een complexe situatie als een klinische setting. De grote uitdaging voor opleiders en stageleiders bestaat erin hen inzicht te geven in deze complexiteit van de stagesituatie als leeromgeving. In een introductiedag op de stage werd aan de hand van dit kader met de stagiairs het gesprek aangegaan over de stage. Het begrippenkader van componenten en spanningsvelden bood op die manier letterlijk een taal om zowel met stageleiders als met stagiairs op een meer systematische manier te spreken over leerervaringen tijdens de stage.

\section{Besluit}

De bespreking van stage-ervaringen in termen van componenten en spanningsvelden doet ons inziens recht aan de complexiteit van de klinische leeromgevingen, maar stelt opleiders en stageleiders ook voor nieuwe uitdagingen. Het bewaken van de kwaliteit van het leren tijdens de stage kan niet eenvoudigweg gebeuren door middel van gestandaardiseerde procedures, competentielijsten, et cetera. Ofschoon planmatige sturing zeker waardevol is, mag men niet vergeten dat stages complexe en in belangrijke mate onvoorspelbare leeromgevingen zijn. De leerkansen tijdens stages zijn dus rijker, breder dan wat zich vooraf laat vastleggen in opdrachten en richtlijnen. Opleidingsverantwoordelijken staan voor de opdracht die leerkansen te erkennen en ruimte te (blijven) geven in de stage, maar tegelijkertijd in adequate ondersteuning te voorzien voor de stagiairs die ermee geconfronteerd worden. Het hier ontwikkelde begrippenkader kan daarbij als inspirerend en structurerend richtsnoer dienen.

\section{Dankwoord}

Met dank aan Johan Beullens en Hilde Groenen voor het becommentariëren van eerdere versies. 


\section{Literatuur}

1. Daelmans HE, Hoogenboom RJ, Donker AJ, Scherpbier AJ, Stehouwer CDA, Vleuten CP van der. Effectiveness of clinical rotations as a learning environment for achieving competences. Med Teach 2004;26:305-12.

2. Pitkala KH, Mantyranta T. Professional socialization revised: medical students' own conceptions related to adoption of the future physician's role - a qualitative research. Med Teach 2003;25:15560.

3. Jolly BC. Bedside manners. Teaching and learning in the hospital setting. Maastricht: Universitaire Pers; 1994.

4. Remmen R, Denekens J, Scherpbier AJJA, Vleuten CPM van der, Hermann I, Puymbroeck $\mathrm{H}$ van, et al. Evaluation of skills training during clerkships using student focus groups. Med Teach 1998;20:428-32.

5. Remmen R, Denekens J, Scherpbier AJJA, Hermann I, Vleuten C van der, Royen P van, et al. An evaluation study of the didactic quality of clerkships. Med Educ 2000;34:460-4.

6. Hem-Stokroos HH van der, Scherpbier AJJA, Vleuten $\mathrm{C}$ van der, Vries H de, Haarman HJTHM. How effective is a clerkship as a learning environment? Med Teach 2001;23:599-604.

7. Irby DM. Teaching and learning in ambulatory care settings: a thematic review of the literature. Acad Med 1995;70:898-931.

8. Dolmans D, Schmidt A, Beek J van der, Beintema M, Gerver WJ. Does a student log provide a means to better structure clinical education? Med Educ 1999;33:89-94.

9. Hoffman K, Donaldson J. Contextual tensions of the clinical environment and their influence on teaching and learning. Med Educ 2004;38:44854.

10. Prideaux D, Alexander H, Bower A, Dacre J, Haist S, Jolly B, et al. Clinical teaching: maintaining an educational role for doctors in the new health care environment. Med Educ 2000;34:820-6.

11. Kelchtermans G. Reflectief ervaringsleren voor leerkrachten. Een werkboek voor opleiders, nascholers en stage-begeleiders. Mechelen: Wolters Plantyn; 2001.

12. Bullough RV, Gitlin AD. Becoming a student of teaching. Linking knowledge production and practice. NY: Routledge Falmer; 2001.

13. Kvale S. Inter Views. An introduction to qualitative research interviewing. CA: Sage; 1996.

14. Schön DA. The reflective practitioner: how professionals think in action. NY: Basic Books; 1983.

15. Fielding N, Fielding J. Linking data. Beverly HillsLondon: Sage; 1986.

16. Yin RK. Applications of case study research. Newbury Park/London/New Delhi: Sage; 1993.
17. Merrian SB. Qualitative research and case study applications in education. San Francisco: Jossey Bass; 1998.

18. Delva MD, Kirby J, Shultz Z, Godwin M. Assessing the relationship of learning approaches to workplace climate in clerkship and residency. Acad Med 2004;79:1120-6.

19. Kilimister SM, Jolly BC. Effective supervision in clinical practice settings: a literature review. Med Educ 2000;34:827-50.

20. Jacobs JCG, Bolhuis S, Bulte JA, Holdrinet RSG. Ervaringen van co-assistenten in de eerste twee weken van een vernieuwde klinische fase. Tijdschrift voor Medisch Onderwijs 2004;23:178-85.

21. Shamroth AJ, Haines AP. Student assessment of clinical experience in general surgery. Med Teach 1992;14:355-62.

22. Seabrook M. Clinical students' initial reports of the educational climate in a single school. Med Educ 2004;38:659-69.

23. Hem-Stokroos HH van der, Daelmans HEM, Vleuten CPM van der, Haarman HJThM, Scherpbier AJJA. The impact of multifaceted educational structuring on learning effectiveness in a surgical clerkship. Med Educ 2004;38:879-87.

24. Hem-Stokroos HH van der, Daelmans HEM, Vleuten van der CPM, Haarman HJThM, Scherpbier AJJA. A qualitative study of constructive clinical learning experiences. Med Teach 2003;25:120-6.

25. Hauer KE, Teherani A, Wiese J, Fenton C. A strategy to standardize the learning of core clerkship objectives. Adv Health Sci Educ 2003;8:213-21.

26. McGrae McDermott M, Curry RH, Conrad Still F, Martin G. Use of learning contracts in an office based primary care clerkship. Med Educ 1999;33:374-83.

27. Maudsley G, Strivens J. Promoting professional knowledge, experiential learning and critical thinking for medical students. Med Educ 2000; 34:535-44.

De auteurs:

Mw. drs. Ann Deketelaere is onderwijspedagoog en medewerker aan de Dienst Onderwijs van de Faculteit Geneeskunde. Ze is betrokken bij de hervorming van het stagejaar.

Prof. dr. Geert Kelchtermans is onderwijspedagoog en hoofd van het Centrum voor Onderwijsbeleid en -vernieuwing van de Faculteit Psychologie en Pedagogische Wetenschappen.

Mw. prof. dr. Elke Struyf is onderwijspedagoog en hoofd van de Dienst Onderwijs van de Faculteit Geneeskunde. Prof. dr. Paul De Leyn is thoraxchirurg en coördinator van de stage in het derde jaar arts van de Faculteit Geneeskunde.

Allen zijn verbonden aan de Katholieke Universiteit Leuven. 


\section{Correspondentieadres:}

Mw. drs. Ann Deketelaere, Dienst Onderwijs, Faculteit

Geneeskunde, Minderbroederstraat 17, B-3000 Leuven,

België, tel: 00-32-16-337530, fax: 00-32-16-337501,

Ann.deketelaere@med.kuleuven.ac.be.

\section{Summary}

Introduction: Clerkships are an essential component of medical education, but not all clerkships yield the appropriate and expected learning results. We performed an exploratory study of the clinical learning process in undergraduate medical education and its determinants. The study was performed among students in year 6 of the curriculum of the Faculty of Medicine, Katholieke Universiteit Leuven, Belgium. We studied learning experiences in the clinical setting from the perspective that these experiences are determined by the meaningful interaction between students and the clinical environment (supervisors in particular).

Method: The study focused on students' perceptions of clerkship experiences. That is why we used qualitative research methods. We followed eight students in two different hospitals for a period of one day (student-shadowing). Interviews with the students and their supervisors provided additional information.

Results: The data analysis revealed five components of experiential learning during clerkships. The components represent various dynamics in the clinical environment where students are constantly required to (re-)define their position: (1) the clerkship agenda (working vs learning), (2) supervisor characteristics (assessor vs coach),(3) the characteristics of the workplace (education vs service), (4) students' attitudes (passive vs pro-active) and (5) learning activities (informal vs formal). These components constitute a conceptual framework that can be used in studies of the learning processes during clerkships.

Discussion: The components of experiential learning and their inherent dynamics offer a conceptual framework that can be used to define and analyse how students learn during clerkships. They can be used as a starting point for discussions among supervisors and academic teachers about the quality of the clinical learning environment and they may also help to provide insight into the position of students. In addition, this conceptual framework may help students to take more responsibility for their learning during clinical clerkships. (Deketelaere A, Kelchtermans G, Struyf E, De Leyn $P$. The dynamics of the clinical learning environment. An exploratory study of clerkship experiences. Dutch Journal of Medical Education 2005;24(3):103-112.) 